Original Research Paper

\title{
Fluid-Solid Coupling Analysis on Evolution of In-Situ Stress Field by Water Injection in Oilfield
}

\author{
${ }^{1,2}$ Jianjun Liu, ${ }^{1,2}$ Yongxiang Zheng, ${ }^{2}$ Bohu Zhang, ${ }^{3}$ Xiaoyong Leng and ${ }^{3}$ Yuanping Li

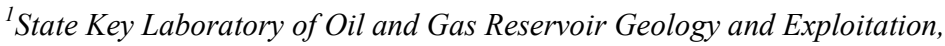 \\ Southwest Petroleum University, Chengdu, China \\ ${ }^{2}$ School of Geoscience and Technology, Southwest Petroleum University, Chengdu, China \\ ${ }^{3}$ No.8 Oil Production Company of Daqing Oilfield Limited Company, Daqing 163514, China
}

\author{
Article history \\ Received: 27-03-2017 \\ Revised: 28-03-2017 \\ Accepted: 05-05-2017 \\ Corresponding Author: \\ Yongxiang Zheng and \\ Jianjun Liu \\ State Key Laboratory of Oil \\ and Gas Reservoir Geology and \\ Exploitation, Southwest \\ Petroleum University, \\ Chengdu, China and \\ School of Geoscience and \\ Technology, Southwest \\ Petroleum University, \\ Chengdu, China \\ Email: yongxiangzheng@163.com \\ and liujj0906@163.com
}

\begin{abstract}
Water injection in oilfield may break initial balance of reservoir and lead to re-distribute of stress and deformation of strata. For further research of the evolution characteristics of in-situ field by water injection, the influence on reservoir by water injection was analyzed and different variables were set to study the effects of depth, injection-withdraw ratio and elastic modulus on strain and stress of strata based on fluid-solid coupling theory. Research shows that: As the water injection, the formation pressure around injection well is greater than that of the production well and the effective stress around injection well is less than that of production well. The deeper the formation is, the smaller the normal strain and vertical displacement are. Besides, the largest shear strain is on the top of reservoir, while the smallest is in central reservoir and different injection-withdraw ratios have significant influence on formation pressure. Elastic modulus mainly influences the deformation of the formation and deformation size is negatively related to the elastic modulus. This study provides a reference for casing damage under the effect of water injection.
\end{abstract}

Keywords: Water Injection, In-Situ Stress Field of Strata, Flow-Solid Coupling, Deformation of Strata

\section{Introduction}

To maintain the reservoir pressure and improve recovery rate of crude oil, water injection is applied in oil field. The initial pore pressure field is in a balance state before production. However, the balance state becomes turbulent due to the water injection and oil production, which would cause the re-distribution of the pressure field.

There are many researchers study about the responses of pore pressure and stress induced by water injection. Based on the strata damage caused by water injection, the shear failure mechanism was studied by Xiaolan and Jianjun (2010). Using dual-porosity model, Liu et al. (2016; Li, 2016) studied the pressure change and reservoir matrix deformation in the process of carbon dioxide injection. Tao (2011) analyzed the mechanics of casing damage and reservoir's deformation induced by water injection and the mechanism of brittle fracture and fault activation of Sandstone during water injection was studied by Elli et al. (2015). Sun et al. (2015) carried out a study on the mechanism of generation and propagation of crack in unsaturated sandstone. Zhang et al. (2015) studied the mechanism of fracture seepage and analyzed the influence of injection velocity and fluid channel on seepage. Based on the fracture of rock mass, the propagation mechanism of crack under stress is analyzed by Chen and Liu (2015). Orlic's study show that the chemical action of water would weaken the strength of rock mass (Orlic et al., 2011).

The interaction between the seepage field and stress field brings about the deformation and destruction of strata and causes the reactivation and extension of faults. Besides, the strength of rocks declines when water immersed in rocks after water injection. With the reduction of strength, the rocks that is stable at initial balance stage would deform and come into instability. Meanwhile, when the swelling rocks meet water, the rock volume increases, which squeezes the surrounding rocks and changes the stress field. The dilation and internal damage of rocks induced by change of mineral compositions and micro structure can decline the macro 
strength of rocks (Yanqing, 2009). Those instable behaviors give birth to casing damage which has a bad influence on normal production of oil field. So, it is critical to study the deformation response of strata induced by water injection.

With the development of the multi fields coupling theory, a lot of researchers give their considerations to the stress and strain model under water injection with multi fields. Shanpo et al. (2011) established the stressseepage-creep damage model of mudstone. The thermaldynamic constitutive model of rock creep was established by Shuang et al. (2016). The fluid solid coupling model of reservoir was established and was applied to reservoir deformation and casing damage by Yu et al. (2015). Ji et al. (2011) established the model of temperature, seepage and stress field and the finite element method was applied to study about casing damage. Besides, a finite element method was used to establish the coupling model of seepage stress temperature chemistry in the process of injecting $\mathrm{CO}^{2}$ into the formation by Yin et al. (2011). Luo et al. (2015) gave a semi-analytical model of temperaturestress coupling in the process of geothermal exploitation. Based on the fluid-solid coupling theory, Yao and Liu (2015) analyzed the stress and deformation near the wellbore with water flooding. For the prevention of casing damage, the stress and deformation of strata during steam drive were analyzed by Zheng (2009). Jinsheng (2012) analyzed the site deformation with interaction theory. With the help of multi field coupling method, using reservoircap rock model, Rutqvist et al. (2009) studied the stress change of reservoir in the process of injection, gave focus on the influence of liquid migration on stress changes and then analyzed the tensile failure and shear failure mechanism. Shen et al. (2015a; 2015b; Kim and Moridis, 2015) thought that the anisotropy, rock strength parameters, initial porosity, initial saturation and injection condition had an important influence on strata deformation and fault activity. To sum up, the stress and deformation responses by water injection are the results of multiple factors.

The strata deformation and destruction is the main reason for casing damage in oilfield. Therefore, the response of formation induced by injection is the key points to prevent casing damage. In order to further study about the influence of water injection on stress and deformation, according to the production conditions of oil field, this paper first analyzed the overall effect of water injection on reservoir based on the fluid solid coupling theory. Then according to the formation depth, production control and rocks' strength parameter, three different variables, depth, Injection-Withdraw Ratio (IWR) and elastic modulus, were set respectively to study the stress and deformation response.

\section{Model and Experiment}

\section{Mathematical Model}

The mathematical model of the stress and strain field of fluid-solid coupling theory of the continuous medium under the condition of vertical compression and permeability change is as follows:

$$
\frac{3 K_{V}\left(\sigma_{e}\right)+G\left(\sigma_{e}\right)}{3} \frac{\partial \varepsilon_{V}}{\partial i}-G \nabla^{2} u_{i}+\frac{\partial p}{\partial i}-F_{i}=0
$$

and:

$$
K_{V}\left(\sigma_{e}\right)=\frac{E\left(\sigma_{e}\right)}{3(1-2 v)}, G\left(\sigma_{e}\right)=\frac{E\left(\sigma_{e}\right)}{2(1-2 v)}
$$

Where:

$K_{V}=$ The volume elastic modulus $(\mathrm{KPa})$

$G=$ The shear modulus (KPa)

$\sigma_{e}=$ The effective stress $(\mathrm{KPa})$

$\varepsilon_{v}=$ The volume strain (1)

$p=$ The pore pressure $(\mathrm{KPa})$

$F_{i}=$ The stress of body $(\mathrm{KPa})$

$E=$ The elastic modulus $(\mathrm{KPa})$

$\mathrm{N}=$ The passion's ratio (1)

Due to $E=E\left(\sigma_{e}\right)$ is a function of effective stress, so $K_{\nu}\left(\sigma_{e}\right)$ and $G\left(\sigma_{e}\right)$ are the function of effective stress. The mathematical model of seepage field is as follows:

$\nabla \cdot\left[\frac{k\left(\sigma_{e}\right)}{\mu} \cdot \nabla(p+\rho g z)\right]=n\left(\sigma_{e}\right) \beta_{p} \frac{\partial p}{\partial t}-\frac{\partial \varepsilon_{V}}{\partial t}$

Where:

$k=$ The permeability $(\mathrm{mD})$

$\mu=$ The dynamic viscosity coefficient (cp)

$\rho=$ The density of fluid $\left(\mathrm{kg} / \mathrm{m}^{3}\right)$

$g=$ The gravitational acceleration, $9.8 \times 10^{-3} \mathrm{~kg} /\left(\mathrm{m}^{2} \cdot \mathrm{s}^{2}\right)$

$z=$ The potential head $(\mathrm{m})$

$n=$ The porosity (1)

$\beta=$ The correction factor (1)

and:

$$
k=k\left(\sigma_{e}\right), n=n\left(\sigma_{e}\right)
$$

Both of them are function of effective stress. Equation 3 and 4 describe the relationship of stress and seepage:

$k\left(\sigma_{e}\right)=k_{0} \exp \left(-\alpha_{1} \sigma_{e}\right)$

$n\left(\sigma_{e}\right)=n_{0} \exp \left(-\alpha_{2} \sigma_{e}\right)$ 
Where:

$k_{0}=$ The initial permeability $(\mathrm{mD})$

$n_{0}=$ The initial porosity (1)

$\alpha=$ An undetermined coefficient (1)

According to effective stress theory, the effective stress is related to total stress and pore pressure of reservoir, which is described by Equation 5:

$$
\sigma_{e}=\sigma-\alpha p
$$

where, $\sigma$ is the total stress $(\mathrm{KPa})$.

According to Hooke's elastic law:

$$
\sigma_{e}=E\left(\sigma_{e}\right) \varepsilon_{\mathrm{V}}
$$

Combined Equation $1 \sim 6$ with the boundary condition and initial condition, the mathematical model is described based on fluid-solid coupling theory.

\section{Numerical model}

A quarter of five spots reservoir model containing $20 \times 20 \times 11$ grids is shown in Fig. 1. There are an Injection well (INJ1) and a Production well (PRO1). The top depth of model is $1200 \mathrm{~m}$ and the thickness of model is $60 \mathrm{~m}$. The porosity is 0.25 . Besides, the horizontal permeability is $100 \mathrm{mD}$, while vertical permeability is $10 \mathrm{mD}$. An initial stress condition, 35 $\mathrm{MPa}$ in horizon and $42 \mathrm{MPa}$ in vertical, is set. As for strength parameters, the elastic modulus is $2.9 \mathrm{e} 5 \mathrm{MPa}$ and the Poisson's ratio is 0.25 . For the $1 / 4$ five spots pattern, the boundary of the model is symmetrical, so the boundary conditions of the model are that the bottom bedrock of the model and the displacement of the four lateral boundaries are restricted, while the top of the reservoir is a stress boundary.

\section{The Stress and Deformation Response of Strata with Different Variables}

The formation deformation caused by water injection is affected by many factors. Because the stress field and deformation field caused by water injection are in a certain symmetry and casing damage are found more frequently around the injection well in site field. The grid $(5,5)$ around the injection well is set as the research object to study the influence of different factors on the formation deformation.

\section{The Strata Response of Depth}

The strata response of different depth, the top, center and bottom of reservoir, are obtained after numerical simulation to conclude the regularity of stress field and seepage field considering depth based on fluid-solid coupling theory.

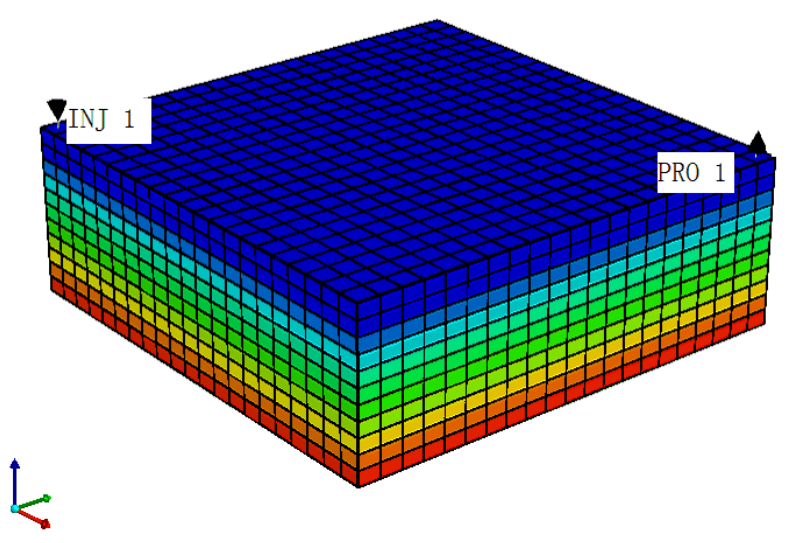

Fig. 1. Numerical model

\section{The Strata Response of Injection-Withdraw Ratio (IWR)}

Water injection breaks the original balance of reservoir, which results in the redistribution of pressure. Different injection conditions have a significant influence on pore pressure. Three designs of different IWRs, 3/2, 1 and 2/3, are set to study the influence of IWR on the reservoir pressure and deformation.

\section{The Strata Response of Elastic Modulus}

The deformation of the rock mass is affected by the stress. Because of the deep buried depth, rocks can be considered as elastic medium at a certain stage. The relationship between stress and strain can be expressed by the elastic modulus of rocks. Therefore, the elastic modulus of $\mathrm{E}=1.5 \mathrm{e} 5 \mathrm{MPa}$ and $\mathrm{E}=2.9 \mathrm{e} 5 \mathrm{MPa}$ were set up to study the stress and strain of the formation.

\section{Results and Analysis}

\section{Distribution of Pore Pressure after Water Injection}

The initial pressure of reservoir in equilibrium is broken by the water injection with high pressure in the injection well and the pressure relief in the oil well, resulting in the re-distribution of formation pressure. Under a certain condition of injection and production, the formation pressure reaches at new equilibrium after a certain period of injection time. At the same time, the pressure value around the injection well is the largest and the pressure value around the oil production well is the smallest. The formation pressure between the injection well and the production well is gradually changed from large to small, besides the pressure gradient is the largest near two wells.

Figure 2 shows the spatial distribution of formation pressure around oil well. It can be seen that the influence degree of pore pressure affected by injection is positively correlated with the strata depth and the spatial pressure 
distribution is in a pyramid shape, that is, the degree is larger in the lower part. The pore pressure distribution around the oil well is shown in Fig. 3. On the contrary, the spatial distribution is in an inverted-pyramid shape which means that the influence degree of pore pressure is larger on the top.

With the increase of the formation depth, the pressure in the wellbore and reservoir increases. The injection pressure at the bottom of the wellbore is higher than that in the upper part of injection well, which leads to bigger pressure influence degree the bottom of the well. When the crude oil is produced from the upper part of reservoir near the production wellbore, the fluid cannot be supplemented in time, resulting in a fast drop rate of pressure, which leads to bigger pressure influence degree at the upper part of the producing well.

To sum up, for injection well, the deeper the formation depth is, the larger the influence range of pore pressure is. On the contrary, for production well, the deeper the formation depth is, the smaller the influence range of pore pressure is.

\section{Analysis of Formation Deformation after Water Injection}

Figure 4 shows the normal strain on the horizontal plane. As can be seen from the figure, the strain around the two wells is larger than that the region between the two wells and the strain gradient near two wells is the largest. In the vicinity of the oil production well, the strain reaches at the maximum positive value, because the effective stress increases caused by the decrease of formation pressure around the oil well, which results in the compression of the rock mass. In the same way, the effective stress decreases around the injection well, which results in a large strain with dilation.

The distribution of shear strain on the horizontal plane is displayed in Fig. 5. The shear strain around the two wells is larger than that in the region between the two wells and there exists a value of 0 , which means that no shear deformation occurs, in the middle part of the two wells. The absolute value of the shear strain around the wellhead is larger, however the extreme value is not exactly at but near the wellhead. Besides, shear strain is in approximate symmetric distribution in horizon plane.

Figure 6 shows the change of the ground settlement after the water injection using the vertical displacement of strata. The figure illustrates that the vertical displacement of the formation around the injection well is positive and upward. The vertical displacement near the oil production wells is negative and the stratum subsides. Because of the continuity of the formation, the vertical deformation of the formation from the water injection well to the oil production wells is changed from upward to downward gradually.

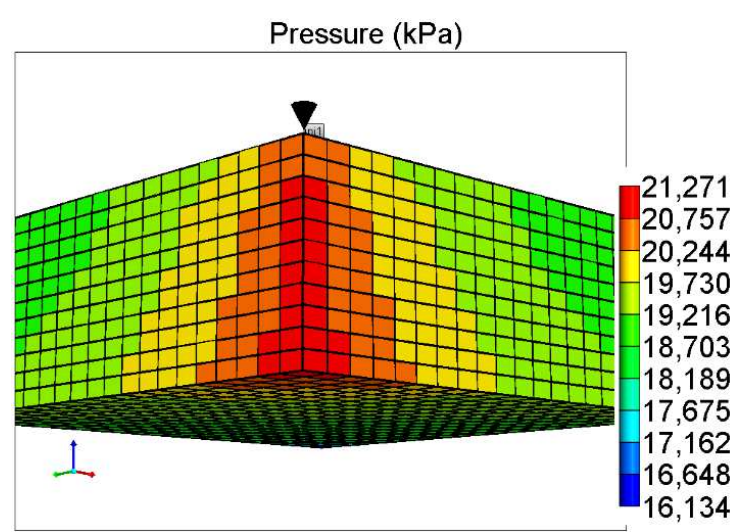

Fig. 2. Pore pressure around injection well

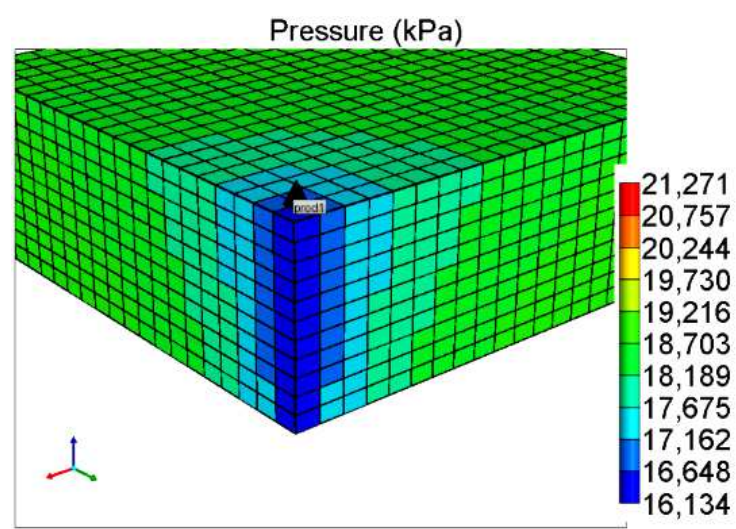

Fig. 3. Pore pressure around production well

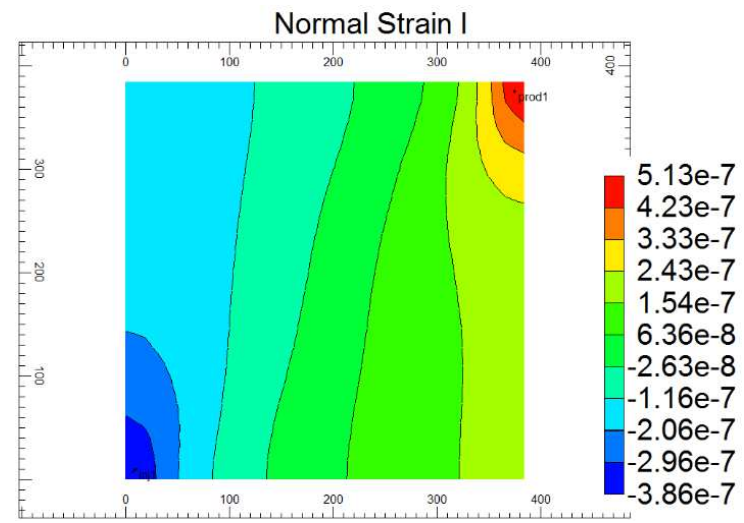

Fig. 4. Normal strain for horizontal panel

This is the results of the effective stress distribution of the strata. The volume of the rock mass will expand for the reason that the effective stress decreases around the injection well, while the confining pressure of the rock mass decreases. The performance of dilation in vertical is the upward of formation. Similarly, the stratum subsides in the vertical direction because that the effective stress increases around the oil well and the volume of rock mass becomes smaller due to compression. 


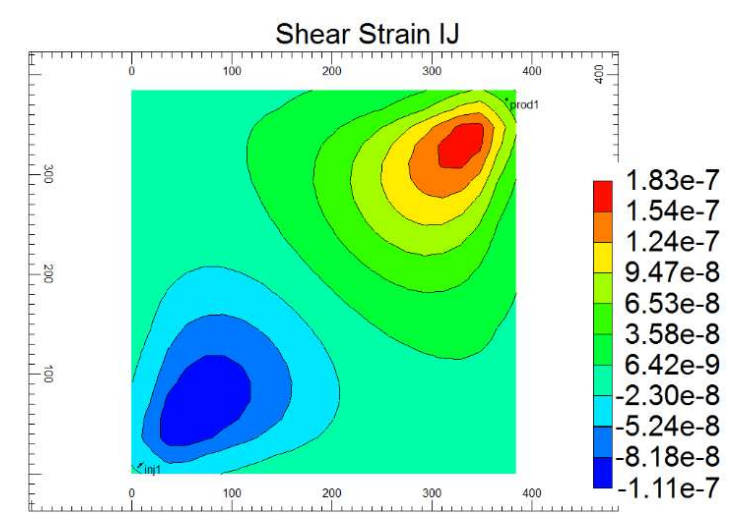

Fig. 5. Shear strain for horizontal plane

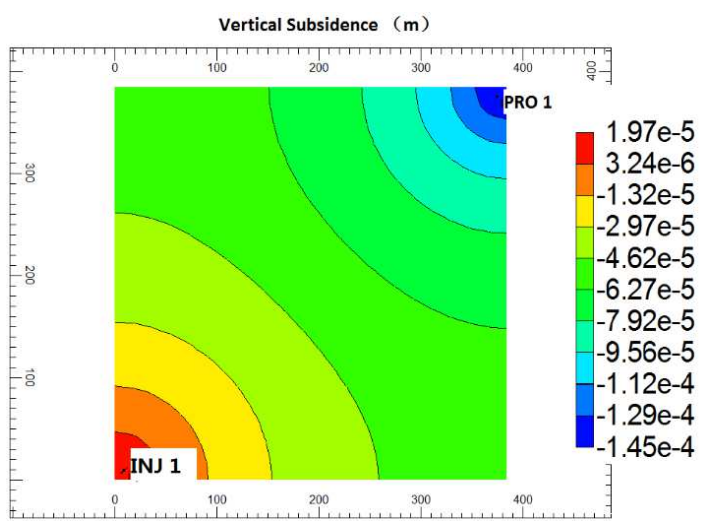

Fig. 6. Vertical displacement for strata

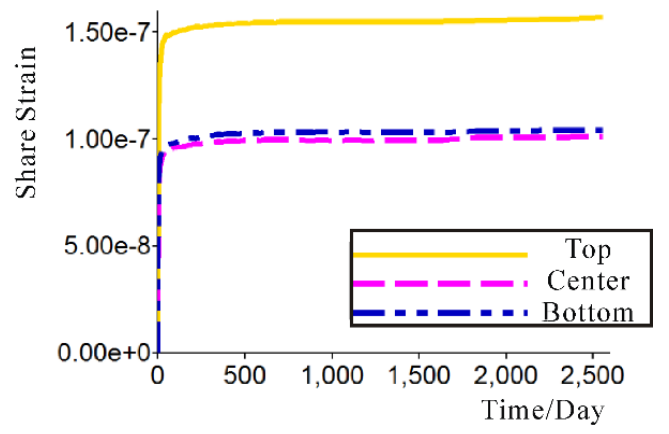

Fig. 7. Shear strain with different depth

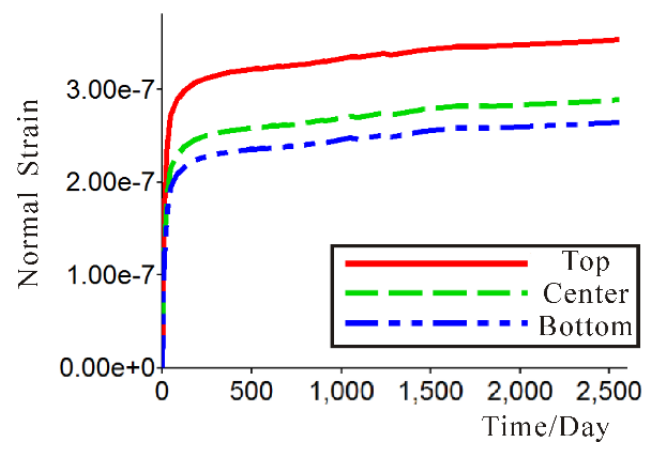

Fig. 8. Normal strain with different depth

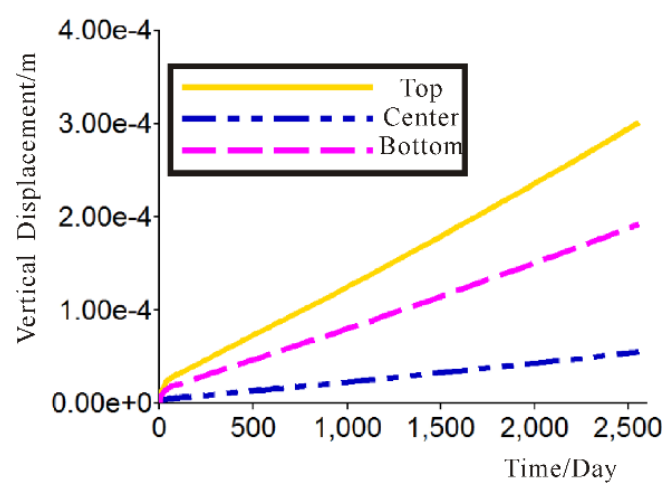

Fig. 9. Vertical Displacement with different depth

\section{Analysis of Formation Deformation Response of Depth}

Figure 7 shows the shear strain at different depth. As can be seen from the figure, the shear strain of the upper part of the reservoir is the largest, while the shear strain in the middle is the smallest. The upper and lower cover of the reservoir is closed, the water cannot be injected and the effect of water injection in the reservoir changes the formation pressure. Therefore, the shear deformation at the top and bottom of the reservoir is larger than that in the middle. Therefore, more attention should be paid to the quality of the casing at the junction of reservoir and cap rocks to reduce the number of casing damage wells.

Figure 8 shows the normal strain at different depth, which is applied to study the strain in the horizontal direction. With the increase of depth, the normal strain of the formation becomes smaller. The normal strain on the upper part of the reservoir is the largest and that of the lower part of the reservoir is the smallest.

Figure 9 shows the variation of displacement at different depth to measure the vertical displacement. From the figure, the reservoir under the water condition uplifts. The change of the upper part of the reservoir is the largest, while the lower part the smallest.

To sum up, in the injection process, the shear strain is large at the top and bottom of the reservoir and small in the internal reservoir. The normal strain and vertical displacement decrease with the increase of reservoir depth.

\section{Analysis of Formation Deformation Response of IWR}

Figure 10 shows the formation pressure under different IWRs. When IWR $>1$, the formation pressure increases with water injection. When IWR $=1$, the formation pressure can keep stable. When $\operatorname{IWR}<1$, the formation pressure will decrease with injection. In a word, the case that IWR $\neq 1$ will lead to the change of formation pressure and that reservoir cannot get the final equilibrium. Therefore, those two schemes are not suitable for long-term development and can only be used to adjust the formation pressure in short term. Because the effective 
stress is related to the formation pressure, the effective stress decreases when the IWR is greater than 1 and the effective stress increases when IWR is less than 1.

Figure 11 is the normal strain of reservoir with different IWRs. It can be seen from the figure that under the condition of equal injection, the normal strain is small and changes smoothly. When IWR $>1$, the normal strain is larger than that of IWR $=1$ and in a state of fluctuations. Under the condition of unbalanced injection and production, the normal strain changes obviously in the initial period and then, the value will be consistent with the result of IWR $=1$.

Figure 12 shows the shear strain under different IWRs. It can be seen that when IWR is less than or equal to 1 , the change of shear strain is consistent and keep balance. When IWR $>1$, the shear strain value is larger than the former. In the initial stage of water injection, the shear strain is larger and then, the shear strain decreases gradually with the time of water injection.

Figure 13 shows the variation of formation displacement under different IWR. From Fig. 13, when IWR $>1$, the formation pressure increases, while the effective stress of rock mass reduces. As a result of it, the formation of the strata is caused by volume expansion. Similarly, when IWR $<1$, the effective stress of rock mass decreases and the strata are compressed and settled.

\section{Analysis of Formation Deformation Response of Elastic Modulus}

The elastic modulus has little effect on effective stress and the stress curves of different elastic modulus are coincident. Due to the fluid-solid coupling effect in the process of water injection, the deformation of rock mass will influence the stress field. In order to study its influence, the stress of the bigger elastic modulus is found small when the curve is enlarged. The reason is that the rock mass with large elastic modulus under the same stress condition in the process of water injection has small volume expansion and small pore volume change. So the pore pressure cannot be released. This causes the smaller stress due that pressure is too large.

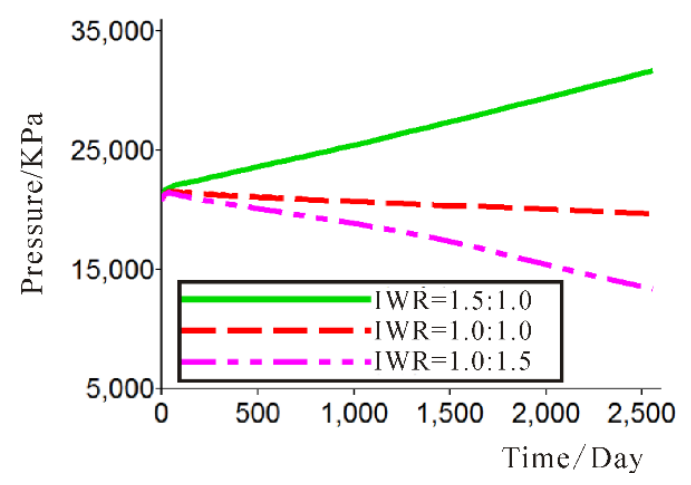

Fig. 10. Pore pressure with different IWRs

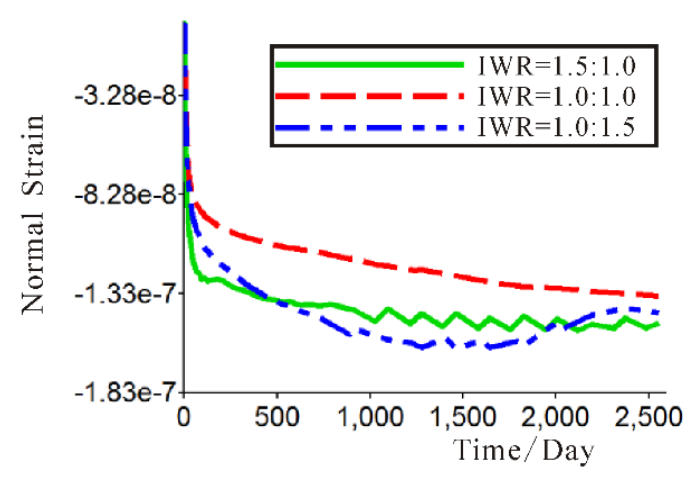

Fig. 11. Normal strainwith different IWRs

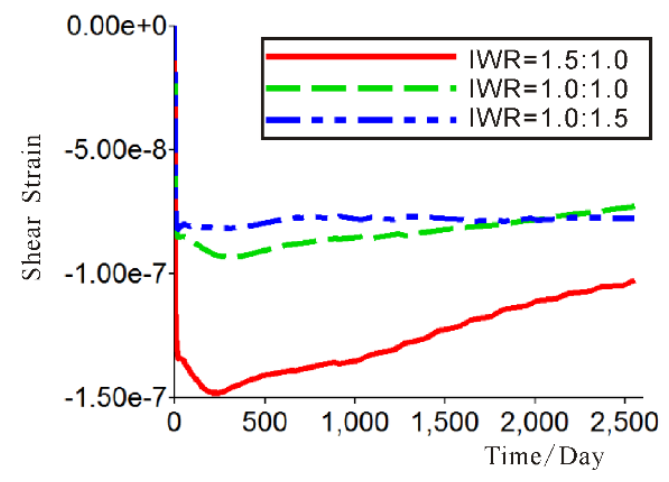

Fig. 12. Shear strainwith different IWRs

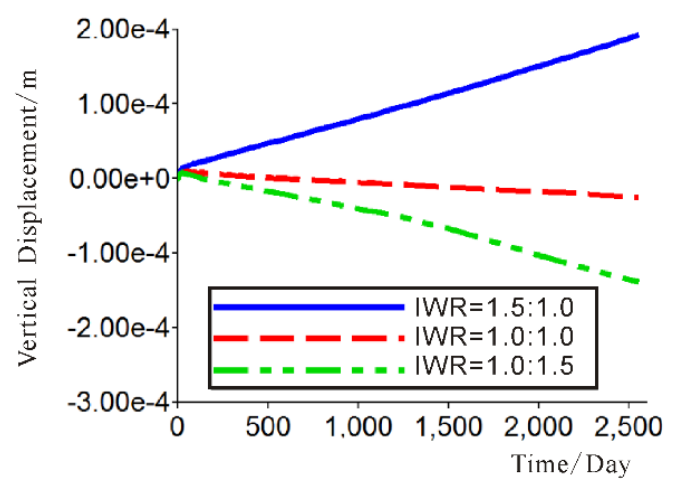

Fig. 13. Vertical displacementwith different IWRs

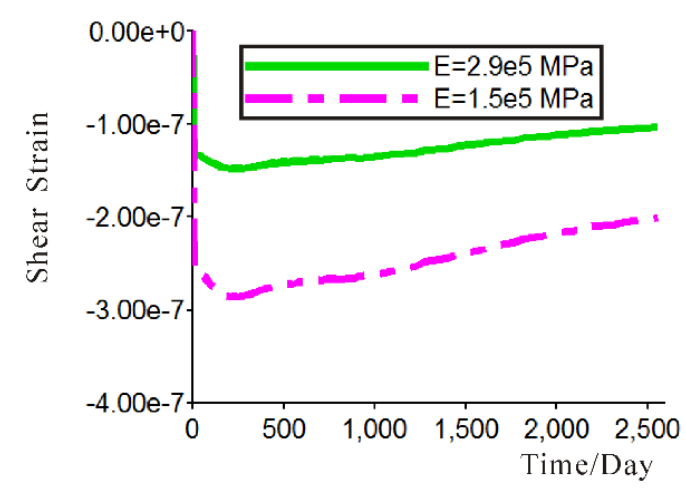

Fig. 14. Shear strain with different E 
Figure 14 is the shear strains of different elastic moduli. The figure illustrates that the shear strain of rock mass with large elastic modulus is small. According to researches, it is found that there is a linear relationship between shear modulus $\mathrm{G}$ and elastic modulus $\mathrm{E}$. Therefore, the shear strain of rock with high elastic modulus is small. Similar to the shear strain, the absolute value of the normal strain is negatively correlated with the elastic modulus. Besides, there is a negative correlation between the vertical settlement of the reservoir and the elastic modulus.

To sum up, the influence of elastic modulus on rock mass is mainly reflected in the deformation. There is a negative correlation between the deformation and the elastic modulus. Because the elastic modulus of mudstone is smaller than that of sandstone, in the process of oil field production, the deformation of mudstone section is higher than that of sandstone. The uneven deformation of sandstone and mudstone leads to casing damage. This is one of the main causes of casing failure in mudstone.

\section{Conclusion}

In this study, a quarter reservoir model of five spots with water flooding was established and a numerical method was used to analyze the overall effect of water injection. The responses of stress and stain with the variation of different parameters were obtained. In this study, three parameters were considered, namely, depth of reservoir, InjectionWithdrawal Ratio (IWR) and elastic modules. The main conclusions of this paper are as follows:

- Water injection leads to redistribution of stress. After a period of injection, the reservoir pressure around injector is higher than producer, while the effective stress around injector is lower than producer and bigger strain and deformation are observed around two wells. Simultaneously, the strain and deformation in the segment between two wells are lower than the surrounding of two wells

- The influence range of reservoir pressure around the injector is in a pear-shaped region which is bigger on the top and smaller on the bottom. A similar but slightly different condition is observed around producer where effective range is smaller on the top and bigger on the bottom, in an inverted-pear-shaped region. The deformation around injection wells is bigger than other region. And more attention should be paid on injection well to prevent casing damage

- With the increase of stratum depth, stress and reservoir pressure increases gradually. The normal strain and vertical subsidence reach maximum value at the top of reservoir and decrease with stratum depth increasing. The shear strain of top and bottom in reservoir is bigger than inner of reservoir and the biggest appears on the top of the reservoir model. So, the critical probabilistic surface of casing damage located in the junction between cap rock and reservoir. The quality of casing near junction should be higher to prevent casing damage

- Different IWRs have a significant effect on reservoir pressure. When IWR $>1(=1.5: 1)$, the pressure increases and the effective stress decreases. Otherwise, when IWR $<1$, the pressure is less and the effective stress is greater. The value of normal strain when IWR $\neq 1$ is bigger than balance injection performance (IWR $=1$ ). Besides, the shear strain increases with IWR $>1$ and is in a low and balance value with IWR $\leq 1$. Therefore, the equal scheme, IWR $=1$, is better to keep formation pressure and prevent casing damage

- Elastic modulus mainly effects the strain and deformation of rocks and strain and deformation are negatively related to the elastic modulus

\section{Acknowledgement}

The research is financially supported by National Science and Technology Major Project of China (Grant No. 2017ZX05037001-005) and I'd like to express my appreciation to Ruiyuan Ma and Zuliang Shao for their discussion about this manuscript.

\section{Funding Information}

The research is financially supported by National Science and Technology Major Project of China (Grant No. 2017ZX05037001). Jianjun Liu received the funding.

\section{Author's Contributions}

Jianjun Liu: Contributed to the conception of the study.

Yongxiang Zheng: Contributed significantly to analysis and manuscript preparation and performed the data analyses and wrote the manuscript.

Bohu Zhang and Xiaoyong Leng and Yuanping Li: Helped perform the analysis with constructive discussions.

\section{Ethics}

The authors declare that there are not ethical issues that could arise after the publication of this study.

\section{References}

Chen, L. and J. Liu, 2015. Numerical analysis on the crack propagation and failure characteristics of rocks with double fissures under the uniaxial compression. Petroleum, 1: 373-381.

DOI: $10.1016 /$ j.petlm.2015.10.009 
Elli, M., S. Stanchits, G. Kwiatek and G. Dresen, 2015. Brittle failure and fracture reactivation in sandstone by fluid injection. Eur. J. Environ. Civil Eng., 97: 535-542. DOI: 10.1080/19648189.2014.896752

Ji, Y.J., L.S. Cheng, J.J. Liu, L.Y. Ye and D. Liu, 2011. A simulation of casing damage considering THM coupling. Petrol. Sci. Technol., 29: 977-987. DOI: $10.1080 / 10916460903514923$

Jinsheng, W., 2012. Fluid solid interaction analysis of site deformation in porous media. Doctoral dissertation, Hebei United University.

Kim, J. and G.J. Moridis, 2015. Numerical analysis of fracture propagation during hydraulic fracturing operations in shale gas systems. Int. J. Rock Mechan. Min. Sci., 76: 127-137. DOI: $10.1016 /$ j.ijrmms.2015.02.013

Li, G., 2016. Numerical investigation of $\mathrm{CO}_{2}$ storage in hydrocarbon field using a geomechanical-fluid coupling model. Petroleum, 2: 252-257. DOI: $10.1016 /$ j.petlm.2016.06.003

Liu, J., G. Li and Z. Yue, 2016. Numerical simulation of co2flooding of coalbed methane considering the fluid-solid coupling effect. Plos One, 11: e0152066-e0152066. DOI:10.1371/journal.pone.0152066

Luo, X., Z. Hou, T. Kracke, Y. Gou and P. Were, 2015. Development of a semi-analytical method to calculate depth-dependent temperature and stress changes: Investigation of micro-seismicity at unterhachinguha gt-2 geothermal well. Environ. Earth Sci., 73: 1-13. DOI: $10.1007 / \mathrm{s} 12665-015-4392-9$

Orlic, B., J.T. Heege and B. Wassing, 2011. Assessing the integrity of fault-and top seals at $\mathrm{CO}_{2}$ storage sites. Energy Proc., 4: 4798-4805. DOI: $10.1016 /$ j.egypro.2011.02.445

Rutqvist, J., D.W. Vasco and L. Myer, 2009. Coupled reservoir-geomechanical analysis of co injection and ground deformations at in Salah, Algeria. Int. J. Greenhouse Gas Control, 4: 225-230. DOI: 10.1016/j.ijggc.2009.10.017

Shanpo, J., C. Weizhong, H.D. Yu and X.L. Li, 2011. Study on seepage stress coupled creep damage model of mudstone (I): Theoretical model. Rock Soil Mechan., 2011: 2596-2602.
Shen, Y.K., H. Liu, H. Wang and H.A. Wu, 2015a. Wellbore instability induced by alternating water injection and well washing with an elasto-plastic erosion model. J. Natural Gas Sci. Eng., 27: 1863-1870. DOI: 10.1016/j.jngse.2015.11.016

Shen, Y., H. Liu, H. Wang, J. Chen and H. Wu, 2015b. Initiation and propagation of wormhole in unconsolidated rock matrix induced by long-term water injection. J. Petrol. Sci. Eng., 127: 93-100. DOI: $10.1016 /$ j.petrol.2015.01.032

Shuang, Y., Z. Zhichao and J. Hongguang, 2016. Thermodynamic constitutive model of rock creep and its application. J. China Univ. Min. Technol., 2016: 1-7. DOI: 10.13247/j.cnki.jcumt.000497

Sun, J., J. Deng, B. Yu and C. Peng, 2015. Model for fracture initiation and propagation pressure calculation in poorly consolidated sandstone during water flooding. J. Natural Gas Sci. Eng., 22: 279-291. DOI: $10.1016 /$ j.jngse.2014.12.004

Tao, J., 2011. Analysis of water injection formation and casing damage based on THM coupling. Doctoral dissertation, Northeast Petroleum University.

Yu, X., C. Xiaoqing and J. Youjun, 2015. Single factor analysis of casing force based on the numerical simulation. J. Southwest Petrol. Univ., 37: 127-134. DOI: $10.11885 /$ j.issn. 1674 5086.2015.03.04. 02

Xiaolan, H. and L. Jianjun, 2010. Mechanism of casing's shear failure in water injection oilfield and its numerical simulation. Chengdu, Peoples R China.

Yanqing, W., 2009. Geohydrauics. 1st Edn., Science Press, Beijing.

Yao, Y. and Y. Liu, 2015. Numerical simulation of fluid structure interaction in strata deformation. Chinese J. Underground Space Eng., 11: 98-102.

Yin, S., M.B. Dusseault and L. Rothenburg, 2011. Coupled thmc modeling of $\mathrm{CO}_{2}$, injection by finite element methods. J. Petrol. Sci. Eng., 80: 53-60. DOI: 10.1016/j.petrol.2011.10.008

Zhang, Q., Y. Ju, W. Gong, L. Zhang and H. Sun, 2015. Numerical simulations of seepage flow in rough single rock fractures. Petroleum, 1: 200-205. DOI: $10.1016 /$ j.petlm.2015.09.003

Zheng, C., 2009. Research on casing damage mechanism of steam flooding well group based on numerical simulation. Doctoral dissertation, Wuhan Polytechnic University, Wuhan, China. 